MYCOPLASMA

\title{
Signs and symptoms of urethritis and cervicitis among women with or without Mycoplasma genitalium or Chlamydia trachomatis infection
}

\author{
L Falk, H Fredlund, J S Jensen
}

Sex Transm Infect 2005;81:73-78. doi: 10.1136/sti.2004.010439

See end of article for authors' affiliations anther. affiliations

Correspondence to: Lars Falk, Department of Dermatology and Venereology, University Hospital, Örebro, SE 70185 Örebro, Sweden; lars.falk@orebroll.se

Accepted for publication 29 April 2004
Objectives: To study the prevalence, symptoms, and signs of Mycoplasma genitalium and Chlamydia trachomatis infections in women attending a Swedish STD clinic, accessible for both sexes, and in a group of young women called in the cervical cancer screening programme.

Methods: A cross sectional study among female STD clinic attendees in Örebro and a study among women called for Papanicolaou smear screening. Attendees were examined for urethritis and cervicitis. First void urine and endocervical samples were tested for $M$ genitalium and $C$ trachomatis.

Results: The prevalence of C trachomatis and M genitalium in the STD clinic population was 10\% (45/465) and $6 \%(26 / 461)$, respectively. Dual infection was diagnosed in four women. In the cancer screening group of women the corresponding prevalence was $2 \%(1 / 59)$ and $0 \%$, respectively. Among the STD clinic attendees there were no significant differences in symptoms (32\% v 23\%, RR 1.4, 95\% Cl 0.6 to 3.4 ) or signs $(71 \%$ v $50 \%$, RR $1.4,95 \% \mathrm{Cl} 0.9$ to 2.3 ) between $C$ trachomatis and $M$ genitalium infections. Microscopic signs of cervicitis were significantly more common among $M$ genitalium and $C$ trachomatis infected women than in the cancer screening group of women. 56\% (15/27) of male partners of $M$ genitalium infected women were infected with $M$ genitalium compared to $59 \%$ of male partners of $C$ trachomatis infected women who were infected with $C$ trachomatis $(p=0.80)$.

Conclusions: $M$ genitalium is a common infection associated with cervicitis and with a high prevalence of infected sexual partners supporting its role as a cause of sexually transmitted infection.
M ycoplasma genitalium was isolated originally from the urethra of two men with non-gonococcal urethritis (NGU) in 1980. ${ }^{12}$ Isolation of this bacterium is very difficult, but the use of polymerase chain reaction (PCR) technology has consistently shown $M$ genitalium to be a major cause of non-chlamydial non-gonococcal urethritis (NCNGU) among men. ${ }^{2-8}$ There is also increasing evidence that $M$ genitalium causes mucopurulent cervicitis in women ${ }^{9}$ and that it may cause endometritis ${ }^{10}$ and possibly tubal infection with sequelae in the form of ectopic pregnancy or tubal infertility. ${ }^{12}$ Only one published study has failed to show an association between urogenital tract disease and the presence of $M$ genitalium in the female genital tract. ${ }^{13}$ However, no asymptomatic patients were included in that study and surprisingly, as many as $38 \%$ of the women were positive compared with a $C$ trachomatis prevalence of $8 \%$, raising concern about the specificity of the $M$ genitalium assay. Most $M$ genitalium studies in STD clinic outpatients have focused on symptomatic patients with urethritis and have used nonsymptomatic patients as controls. These studies demonstrate that $M$ genitalium, $C$ trachomatis, and Neisseria gonorrhoeae are significantly more frequently detected among symptomatic patients than among asymptomatic controls, thus indicating that these bacteria are pathogens of the genital tract. ${ }^{36}{ }^{14}$ This is emphasised by the fact that sexual partners of $M$ genitalium and $C$ trachomatis infected patients harbour the corresponding microbe more often than partners of patients with other STIs. ${ }^{15}$ Thus, in conclusion, the role of $M$ genitalium may not significantly differ from that of genital $C$ trachomatis infection.

Most women with $M$ genitalium, $C$ trachomatis, or $N$ gonorrhoeae infection attending an STD clinic receive treatment immediately after clinical and microscopic examination, because of signs of infection. The microscopic criteria for cervicitis differ and are debatable. In the Scandinavian countries, a widely used criterion is the presence of more polymorphonuclear leucocytes (PMNL) than epithelial cells in vaginal wet smears. However, some investigators claim leucocytosis to appear without evidence of infection during the menstrual cycle especially around midcycle following ovulation. ${ }^{16}{ }^{17}$

The aim of this cross sectional study was to compare signs and symptoms in female STD clinic attendees with $C$ trachomatis and $M$ genitalium infections and to study the prevalence of these bacteria and the rate of infection among sexual partners. A secondary aim was to estimate the value of microscopic examination of wet smears and urethral smears as tools for the diagnosis of cervicitis and urethritis.

\section{METHODS}

\section{Study population}

From 1 February 2000 to 31 July 2000, all female attendees at the Örebro University Hospital STD clinic were included. Data were collected on a detailed standard questionnaire regarding the reasons for attendance, age, symptoms (vaginal discharge, urethral pain during micturition, intermenstrual, or postcoital bleeding, and lower abdominal pain), contraceptive method, day of menstrual cycle, and probable sexually transmitted infections (STI) among partners.

Abbreviations: FVU, first void urine; HPF, high power field; NCNGU, non-chlamydial non-gonococcal urethritis; NGU, non-gonococcal urethritis; NSI, non-specific inflammation; $\mathrm{PCR}$, polymerase chain reaction; PMNL, polymorphonuclear leucocytes; STI, sexually transmitted infections 
Table 1 Symptoms, microscopic signs of urethritis and/or cervicitis among all female STD clinic attendees $(n=465)$

\begin{tabular}{|c|c|c|c|c|c|c|c|c|c|c|c|}
\hline & \multirow{2}{*}{\multicolumn{2}{|c|}{$\frac{\text { Normal smears }}{\text { Urethral smear }}$}} & \multirow{2}{*}{\multicolumn{2}{|c|}{$\begin{array}{l}\begin{array}{l}\text { Urethritis and } \\
\text { normal wet smear }\end{array} \\
\text { Urethral smear }\end{array}$}} & \multirow{2}{*}{\multicolumn{2}{|c|}{$\begin{array}{l}\begin{array}{l}\text { Urethritis and } \\
\text { cervicitis }\end{array} \\
\text { Urethral smear }\end{array}$}} & \multirow{2}{*}{\multicolumn{2}{|c|}{$\begin{array}{l}\text { Cervicitis and } \\
\text { normal urethral } \\
\text { smear } \\
\text { Urethral smear }\end{array}$}} & \multirow{3}{*}{$\begin{array}{l}\text { UND and } \\
\text { WND }\end{array}$} & \multirow{3}{*}{$\begin{array}{l}\text { Symptoms } \\
\text { count (\%) } \\
\text { Count (\%) }\end{array}$} & \multirow{3}{*}{$\begin{array}{l}\text { Bacterial } \\
\text { vaginosis }\end{array}$} \\
\hline & & & & & & & & & & & \\
\hline & $<5^{*}$ & UND & $5-10^{*}$ & $>10^{*}$ & $5-10^{*}$ & $>10^{*}$ & $<5^{*}$ & UND & & & \\
\hline $\begin{array}{l}\text { C trachomatis pos } \\
(\mathrm{n}=41)\end{array}$ & $11 \dagger$ & 1 & 2 & 7 & 3 & 4 & 8 & 1 & 4 & $13(32)$ & $12 / 36(33)$ \\
\hline $\begin{array}{l}\text { M genitalium pos } \\
(\mathrm{n}=22)\end{array}$ & 11 & 0 & 0 & $2 \ddagger$ & 0 & 3 & 6 & 0 & 0 & $5(23)$ & $5 / 22(23)$ \\
\hline $\begin{array}{l}\mathrm{Mg} \text { and } \mathrm{Ct} \text { pos } \\
(\mathrm{n}=4)\end{array}$ & 0 & 0 & 0 & 1 & 0 & 2 & 1 & 0 & 0 & $2(50)$ & $2 / 4(50)$ \\
\hline $\begin{array}{l}\text { Urethritis and/ } \\
\text { or cervicitis, } \\
\text { negative tests ( } n=155 \text { ) }\end{array}$ & 0 & 0 & 18 & 37 & 8 & 26 & 65 & 1 & 0 & $65(42)$ & $30 / 155$ (19) \\
\hline $\begin{array}{l}\text { The rest of attendees } \\
(n=243)\end{array}$ & $237 \dagger$ & 2 & 0 & 0 & 0 & 0 & 0 & 0 & 4 & $53(22)$ & $26 / 243(11)$ \\
\hline Total $(n=465)$ & 259 & 3 & 20 & 47 & 11 & 35 & 80 & 2 & 8 & $138(30)$ & $73 / 456(16)$ \\
\hline
\end{tabular}

\section{Women in a comparison group (cervical cancer screening group)}

Women $(n=157)$ aged $22-26$ years who were registered as residents in an inner city area of Örebro on 30 June 2002, and called for routine Papanicolaou smear screening in the national cervical cancer screening programme were invited to participate in the study by a letter attached the call for screening. The women had the opportunity to give consent via email, phone, or by writing a letter. LF contacted those women who had not replied by phone or letter. Women agreeing to participate were asked about current symptoms, current or recent antibiotic treatment, contraceptive method, and day of menstrual cycle at the time of examination and sampling. This group of women who participated is henceforth designated the screening group. This part of the study was conducted in September and in October 2002. LF examined and took samples from all participants, and performed the microscopic examination.

\section{Sampling}

Patients

A total of 465 women between 15 and 54 years of age (median 24 years) were included. Four women were not examined or tested for $M$ genitalium since they were referred from primary health care with a confirmed $C$ trachomatis genital infection. The remaining 461 women were examined.

Samples were taken from the posterior and lateral vaginal fornicies for wet smear examination in $10 \% \mathrm{KOH}$ and in $0.9 \%$ $\mathrm{NaCl}$, respectively, using a $10 \mu \mathrm{l}$ inoculation loop. An endocervical swab and a sample taken with a blunt curette from the distal urethra were obtained, and the smears were stained with methylene blue.

During the study period, seven clinicians participated, but four of those examined $95 \%$ of all patients. All smears were examined with a NikonLabophot microscope. Wet smears and methylene blue stained smears were examined in phase contrast $400 \times$ and at $1000 \times$ magnification, respectively. Cervicitis was defined as more PMNL than epithelial cells in wet smear. Urethritis is generally defined as $>4$ PMNL per high power field (HPF) in more than four $\mathrm{HPF},{ }^{18}$ but in the current study smears with 5-10 PMNL per HPF were defined as "grey zone urethritis" and >10 PMNL per HPF as urethritis. ${ }^{15}$ Endocervical specimens were obtained, using three sterile aluminium shafted Rayon swabs (Copan,
Brescia, Italy). The first two swabs were used for detection of $C$ trachomatis by culture and were transported in one polypropylene tube (Sarstedt, Nümbrecht, Germany) containing 2-SP medium to the Örebro University Hospital laboratory. The third swab was transported in 2-SP medium to Statens Serum Institut in Copenhagen, Denmark, for detection of $M$ genitalium. Before the genital examination, first void urine (FVU) was collected for $C$ trachomatis and $M$ genitalium tests and distributed in two screw capped $13 \mathrm{ml}$ polypropylene tubes (Sarstedt, Nümbrecht, Germany). Sexual partners attending the STD clinic during the study were examined for $C$ trachomatis and $M$ genitalium as described previously. ${ }^{15}$

\section{Women in the screening group}

The procedure described above was performed on women in the screening group. Specimens for wet smear were examined microscopically within 4 hours at the STD clinic. Out of 157 eligible women, 59 (38\%) women between 22 and 26 years of age (median 23) participated in the study. Reasons for not participating (98/157) were: 24 only wanted Pap smear taken, 21 could not be reached but were still registered residents, 18 had moved from town, 11 were abroad, six had had no sexual intercourse, five did not want to give any reason, four had been examined with Pap smear test recently, three were pregnant, two were breastfeeding, two could not get any suitable appointment, and two agreed to participate, but did not attend (dropout).

\section{Microbiological analysis}

One of the tubes containing $5-10 \mathrm{ml}$ of urine and the endocervical specimens was sent the same day to the Department of Clinical Microbiology, Örebro University Hospital, and stored at $2^{\circ}-8^{\circ} \mathrm{C}$. The urine samples were tested by the Cobas Amplicor Chlamydia trachomatis test (Roche Diagnostics Systems, Inc, Branchburg, NJ, USA) as described by the manufacturer.

The other tube containing 5-10 $\mathrm{ml} \mathrm{FVU} \mathrm{and} \mathrm{the} \mathrm{second}$ endocervical specimen was sent the same day by express mail to Statens Serum Institut, Copenhagen, Denmark, for $M$ genitalium PCR test. $M$ genitalium was detected by an inhibitor controlled PCR using primers detecting the $M$ genitalium $16 \mathrm{~S}$ rRNA gene. ${ }^{19}$ All positive results were confirmed by a PCR detecting the $\mathrm{MgPa}$ adhesin gene. ${ }^{20}$ 
Table 2 Signs of urethritis and cervicitis

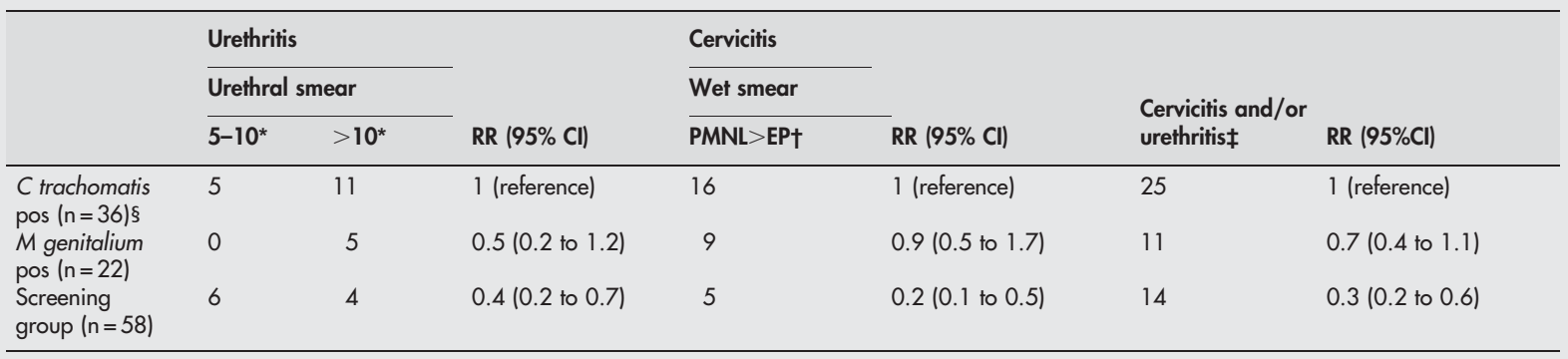

A comparison between STD clinic attendees with Chlamydia trachomatis or Mycoplasma genitalium infection and a screening group of women, without these infections.

Patients with dual $C$ trachomatis and $M$ genitalium infection $(n=4)$ were excluded in comparisons as well as five patients with $C$ trachomatis infection, where smears were not sampled.

*PMNL per HPF.

†Microscopic cervicitis was defined as more PMNL than vaginal epithelial cells (EP) in wet smear.

fUrethritis defined as $>4$ PMNL/HPF.

§Urethral smear was not sampled from one patient, who had a microscopically verified cervicitis.

Endocervical and urethral samples for Neisseria gonorrhoeae (culture) were taken from 65 women. Samples were taken selectively on certain indications and not as a screening test because of the low incidence in Sweden $(0.7 / 100000$ inhabitants-that is, 588 cases in 2000). ${ }^{21}$

For the women in the screening group the same procedures were used, but no sampling for $N$ gonorrhoeae was performed.

\section{Bacterial vaginosis}

Amsel's criteria were used for the diagnosis of bacterial vaginosis. $^{22}$

\section{Follow up}

All patients infected with $C$ trachomatis and/or $M$ genitalium were asked to reattend for a follow up visit 4-5 weeks after commencing antibiotic treatment. As a part of this study the treatment efficacy in $M$ genitalium infected patients was evaluated in an open pilot study. ${ }^{23}$ The results from that study suggest that tetracyclines are not sufficient to eradicate $M$ genitalium, but that azithromycin might be effective. All recent partners of $C$ trachomatis and $M$ genitalium infected patients were notified and asked to attend the STD clinic for $C$ trachomatis and $M$ genitalium testing and genital examination. Recent partners were defined as all partners during the past 6 months before attendance or, if one partner during this period, at least the two latest partners.

\section{Statistical analyses}

The $\chi^{2}$ test and Fisher's exact test, when appropriate, were used to test differences in proportions. Stata statistical software version 8.0 was used for calculating confidence intervals.

\section{RESULTS}

Neisseria gonorrhoeae was not isolated from any patient and no smears were positive for $N$ gonorrhoeae. Urethritis and/or cervicitis (NGU) was detected in $222(48 \%)$ of the 461 women attending the STD clinic and in $15(25 \%)$ of the 59 women in the screening group. In the latter group, one woman was infected with $C$ trachomatis, but none was infected with $M$ genitalium. Among the STD clinic attendees, 45 patients between 16 and 32 years of age (median 22 years) were infected with $C$ trachomatis $(10 \%, 45 / 465)$ and 26 patients between 16 and 39 years of age (median 22 years) were positive for $M$ genitalium $(6 \%, 26 / 461)$. Four chlamydia patients had a concurrent $M$ genitalium infection, and were excluded from further analysis. The remaining 155 women with $M$ genitalium negative non-chlamydial non-gonococcal urethritis and/or cervicitis were between 15 and 51 years of age (median 24 years) $(34 \%, 155 / 457)$. They were considered as having a non-specific inflammation (NSI). Among these, 42 had condylomata and seven had genital herpes infection; these infections themselves might be the cause of cervicitis and/or urethritis.

Among women with NSI, 42\% (65/155) reported symptoms compared with $22 \%(53 / 247)$ of those without urethritis or cervicitis $(p<0.001)$, whereas there was no statistically significant difference in the prevalence of symptoms between $C$ trachomatis and $M$ genitalium infected patients or the other groups of STD clinic attendees (table 1). Bacterial vaginosis was more prevalent among $C$ trachomatis infected women $(35 \%, 14 / 40)$ than among women without urethritis and/or cervicitis $(11 \%, 26 / 243)(\mathrm{p}<0.001)$ but also more common than among the 177 women with non-chlamydial urethritis and/or cervicitis $(20 \%, 35 / 177)$, although this difference did not reach statistical significance $(\mathrm{p}=0.06)$ (table 1$)$.

Table 3 Diagnosis of sexual partners of 24 women infected with $C$ trachomatis (Ct), 17 infected with $M$ genitalium $(\mathrm{Mg})$, four with a dual infection and 43 women with a nonspecific infection (NSI). Percentages presented within parentheses

\begin{tabular}{|c|c|c|c|c|}
\hline \multirow[b]{2}{*}{ Partners' diagnosis } & \multicolumn{4}{|c|}{ Female patients' diagnosis } \\
\hline & $\begin{array}{l}\mathrm{Ct} \\
(\mathrm{n}=24 / 41)\end{array}$ & $\begin{array}{l}\mathrm{Mg} \\
(\mathrm{n}=17 / 22)\end{array}$ & $\begin{array}{l}M g \text { and } C_{t} \\
(n=4 / 4)\end{array}$ & $\begin{array}{l}\text { NSI } \\
(n=43 / 155)\end{array}$ \\
\hline C trachomatis & $19 *(59)$ & $2 *(10)$ & $4^{*}(57)$ & $7(16)$ \\
\hline M genitalium & $1 *(3)$ & $13^{*}(65)$ & $2 *(28)$ & $2(5)$ \\
\hline Non-specific urethritist & $11(34)$ & $5(25)$ & $1(14)$ & $12(29)$ \\
\hline Other diagnoses & $2(6)$ & $1(5)$ & $1(14)$ & $21(50)$ \\
\hline Total number of partners & $32^{*}$ & $20^{*}$ & $7^{*}$ & $42(100)$ \\
\hline
\end{tabular}

*One male partner in each group was both $C$ trachomatis and $M$ genitalium positive.

$\dagger$ Non-specific urethritis indicates urethritis with negative test results for $C$ trachomatis and $M$ genitalium. 

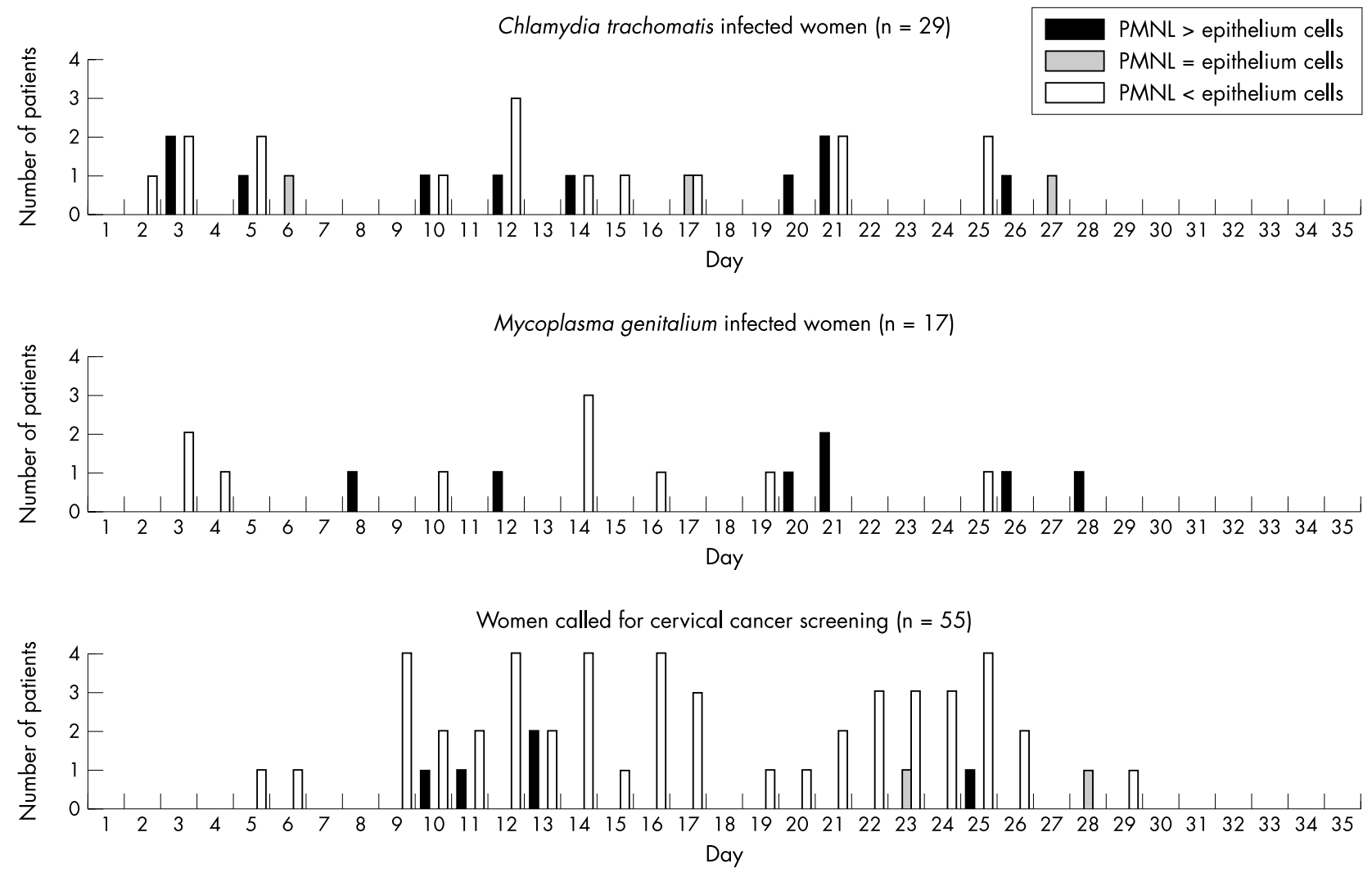

Figure 1 Vaginal wet smear and relation to menstrual cycle day in $C$ trachomatis infected women $(n=29)$, in $M$ genitalium infected women ( $n=17)$, and among women called for cervical cancer screening $(n=55)$.

Among the women in the screening group, three $(5 \%)$ had symptoms (vaginal discharge). This was significantly fewer than the $30 \%(20 / 67)$ of women with symptoms in the group infected with $M$ genitalium and/or $C$ trachomatis $(\mathrm{p}<0.001)$, but also fewer than the $22 \%(53 / 243)$ of women without urethritis or cervicitis in the STD clinic population. Bacterial vaginosis was diagnosed in $14 \%(8 / 58)$ of the women in the screening group, which was significantly lower than the rate among the $C$ trachomatis infected women in the STD clinic population $(p=0.013)$. There was no statistically significant difference in the prevalence of bacterial vaginosis when corresponding comparison was performed between the screening group and the women infected with $M$ genitalium $(\mathrm{p}=0.22)$.

Signs of urethritis and/or cervicitis were seen in $71 \%$ (25/35) of $C$ trachomatis infected and in 50\% (11/22) of $M$ genitalium infected women compared with $24 \%$ (14/58) among the women in the screening group $(\mathrm{p}<0.001)$ and $(\mathrm{p}=0.03)$ for $C$ trachomatis and $M$ genitalium, respectively. Among the $C$ trachomatis and $M$ genitalium negative women in the STD clinic population, $40 \%$ (155/390) had signs (tables 1 and 2). There was no statistically significant difference in the prevalence of signs between the $M$ genitalium infected and the $C$ trachomatis infected women (RR $0.7 ; 95 \%$ CI 0.4 to 1.1 ).

$C$ trachomatis was strongly associated with microscopic signs in the STD population as $25(71 \%)$ of 35 C trachomatis positive women had urethritis and/or cervicitis whereas only $166(40 \%)$ of the 412 C trachomatis negative women had signs $(\mathrm{p}<0.001)$. In contrast, $M$ genitalium could not be shown to be associated with signs, since 11 (50\%) of 22 M genitalium positive women had signs compared to 180 (42\%) of the 425 $M$ genitalium negative women $(\mathrm{p}=0.6)$.

Twenty seven sexual partners of $21 \mathrm{M}$ genitalium infected women were examined and $15(56 \%)$ of them were
$M$ genitalium positive, six $(22 \%)$ were $C$ trachomatis positive of whom two where infected with both $M$ genitalium and $C$ trachomatis and partners of doubly infected women. Correspondingly, 39 partners of $28 \mathrm{C}$ trachomatis positive women were examined and 23 (59\%) of those partners were $C$ trachomatis positive, and three (8\%) were $M$ genitalium positive, of which two men were partners of doubly infected women. Seven $(16 \%)$ of the 42 examined partners of women with NSI were $C$ trachomatis positive, and two (5\%) were $M$ genitalium positive. Both $C$ trachomatis and $M$ genitalium infections were found significantly more often in partners of women with the corresponding infection, than in partners of women with NSI $(\mathrm{p}<0.001$ for both). The diagnosis and number of partners of each group are shown in table 3.

Median menstrual cycle day was day 12 for $C$ trachomatis infected women, day 14 for $M$ genitalium infected women, and day 16 for the screening group. There was no statistically significant difference in the use of oral contraception (OC), which was $70 \%, 68 \%$, and $64 \%$, respectively in the different groups $(p=0.80)$. No cluster pattern of vaginal leucocytosis could be seen in relation to the menstrual cycle in any of the groups (fig 1).

\section{DISCUSSION}

In this cross sectional study among female STD clinic attendees, the prevalence of $C$ trachomatis was higher than that of $M$ genitalium ( $10 \% \vee 6 \%$ respectively) and with only $1 \%$ infected with both bacteria (4/461). In the screening group, only one woman was infected with $C$ trachomatis and none with $M$ genitalium. Only a few true cross sectional studies of female STD clinic populations have been published. In one Swedish study, 85 women were examined during a period of 11 months and the prevalence of $C$ trachomatis and $M$ genitalium was $9 \%$ and $3.5 \%$ respectively. ${ }^{5}$ However, the 
women were not enrolled consecutively and not all women were sampled (Gunnar Johannisson, personal communication). ${ }^{5}$ Another Swedish study reported an $M$ genitalium prevalence of $5 \%$ and a $C$ trachomatis prevalence of $4 \%$ (Carin Anagrius, personal communication). ${ }^{24}$ In a retrospective study of women attending an STD clinic in Seattle, Washington, stored samples from 1984 to 1986 were tested in 2001 and the $M$ genitalium prevalence was $7 \%$ compared with $11 \%$ for $C$ trachomatis. ${ }^{9}$ It is quite likely that $M$ genitalium is less prevalent than $C$ trachomatis, and that $M$ genitalium is not widely spread in a low risk asymptomatic population. This notion is supported by the absence of $M$ genitalium infection among the women in the screening group. Only one study conducted in 1994-6 in France has shown a completely different pattern with an $M$ genitalium prevalence among symptomatic female STD clinic attendees of 38\% (65/170), and a $C$ trachomatis prevalence of $8 \%$ (14/171). ${ }^{13}$

Symptoms of cervicitis and/or urethritis were relatively uncommon, being reported by $30 \%$ of the women in the STD clinic population, and it correlated poorly with the presence of signs of inflammation. However, it is a well known fact that bacterial STIs in women are asymptomatic in a high proportion of the cases. ${ }^{25}{ }^{26}$ In the screening group, significantly fewer women $(3 / 58,5 \%)$ had symptoms. Furthermore, significantly fewer women in this group had bacterial vaginosis than had women infected with $C$ trachomatis. A high prevalence of bacterial vaginosis among $C$ trachomatis infected women has been reported ${ }^{27}$ and it has been suggested that bacterial vaginosis may increase the susceptibility to infection with $C$ trachomatis. ${ }^{28}$

In the present study, $15(56 \%)$ of the 27 male partners of $M$ genitalium infected women tested at the STD clinic had an $M$ genitalium infection. These data emphasise the role of $M$ genitalium as a sexually transmitted pathogen, since only two $(5 \%)$ of the 42 partners of women with NSI were $M$ genitalium positive $(\mathrm{p}<0.001)$. In the 39 male partners of $C$ trachomatis infected women, 23 (59\%) were infected with chlamydia indicating that the concordance rate was about the same for $C$ trachomatis and $M$ genitalium. For the NSI cases, some patients attended because $C$ trachomatis infection was diagnosed in one of their male partners. This might explain the rather high prevalence of $C$ trachomatis (16\%) among their partners. Few studies reporting STIs among partners of $C$ trachomatis or $M$ genitalium infected patients have been published and it would be interesting to study more carefully the negative partner in the couples regarding infection as detected in other anatomical sites and with an intensified sampling on several days. We consider it likely that a significant proportion of the discordant couples were indeed deemed so based on false negative laboratory test results. In another Swedish study the rate of $M$ genitalium infected partners of $M$ genitalium infected women was $31 \%$, ${ }^{24}$ whereas in an English study, the number of $M$ genitalium infected women was too low to find any significant differences in the prevalence of the bacterium among partners. ${ }^{29}$

At STD clinics microscopic examinations of methylene blue or Gram stained urethral and endocervical smears as well as examination of vaginal wet smears are routinely performed. The criteria for male urethritis were defined in $1978^{18}$ but no definition of female urethritis or cervicitis has been established. When the cut of for microscopic urethritis was raised to $>10 \mathrm{PMNL} / \mathrm{HPF}$, as proposed by $\mathrm{Stamm}^{30}$ fewer women in the screening group had this sign whereas all women infected with $M$ genitalium having urethritis had $>10$ PMNL/HPF thus, the specificity of this sign increased. Because of the small number of women, however, the difference did not reach statistical significance.

In Scandinavia, the diagnosis of cervicitis is often based on the presence of more PMNL than vaginal epithelial cells in wet smear. An American study ${ }^{9}$ used the criteria >10 PMNL/ HPF and purulent discharge from the cervical orifice based on findings from an earlier study. ${ }^{30}$ In this study, we compared the presence of microscopic cervicitis between $C$ trachomatis and/or $M$ genitalium infected women and the other STD clinic attendees and between the infected women and the $C$ trachomatis negative women in the screening group. Obviously, the two populations are not directly comparable. It could be assumed that the STD clinic attendees were more likely to exhibit a higher prevalence of sexual risk behaviour than were the screening group, leading to a broader spectrum of STIs and a higher prevalence of different STIs. Only 38\% of women called for Pap smear in the cervical cancer screening programme participated in the study. The reasons for not participating have been described above. We cannot completely exclude the possibility of selection that may bias the results; however, it is not likely that those women who participated would be at a lower risk of catching an STI than those who did not.

De Allende $^{16}$ described variations of the number of leucocytes during the menstrual cycle. Larsson ${ }^{17}$ reported an increase in the number of leucocytes in the vaginal secretions usually once in the menstrual cycle in three middle aged women who were studied during four cycles. In the present study, we found no specific pattern of leucocytosis during the menstrual cycle. However, since our study populations used OC $(64 \%-70 \%)$ they had no ovulation, and thus, the pattern may be obscured or absent. Most young women with high STI risk behaviour use OC, and therefore the findings of De Allende and Larsson might be less important in an STD clinic.

The interpretation of smears depends on several variables: the instrument for sampling, the standard of the microscope and how it is used, the experience of the clinician, and whether stained dry smears or wet smears are examined. This subjective procedure can never be strictly scientifically standardised. We believe that more studies are required on the diagnostic tools for determining the clinically relevant definition of cervicitis and urethritis.

In summary, $M$ genitalium was associated with signs of cervicitis and both $C$ trachomatis and $M$ genitalium infected women transmitted the infections to a large proportion of their sexual partners. More studies are needed to determine

\section{Key messages}

- M genitalium is an important and frequent cause of female lower genital tract infection. This study indicates that infections with $M$ genitalium and $C$ trachomatis are often asymptomatic, and that there are no significant differences between the bacteria in terms of symptoms and microscopic signs

- Partners of $M$ genitalium infected women were often infected with M genitalium and to the same extent were partners of $C$ trachomatis infected women infected with $C$ trachomatis (56\% and 59\%, respectively) supporting the role of $M$ genitalium as a sexually transmitted pathogen

- The absence of $M$ genitalium infection in a group of women called for Papanicolaou smear in a cervical cancer screening programme strongly indicates that $M$ genitalium is a pathogen and not a commensal bacterium

- More studies are needed on the diagnostic tools for determining the clinically relevant definition of cervicitis and urethritis 
the potential of $M$ genitalium infection to cause invasive disease in both women and in men. The high $M$ genitalium prevalence among STD clinic attendees indicates that screening for this pathogen may be rewarding in the STD clinic setting.

\section{ACKNOWLEDGEMENTS}

We thank the staff at the Örebro STD clinic and especially Maritha Holmquist. Birthe Dohn at Statens Serum Institut provided excellent technical assistance. Without the help from Gunbritt Skoglund at the Department of Pathology, Örebro University Hospital and the enthusiasm and help from the midwives Ros-Marie Bromdal, AnnKatrine Kjell, and Elisabeth Pino at Skebäcks vårdcentral, Örebro, the second part of the study could not have been conducted. We also thank Anders Magnuson for statistical advice.

\section{CONTRIBUTORS}

LF initiated the study, examined and sampled most of the patients; he also collected all data and wrote the first draft of the manuscript; HF was responsible for the $N$ gonorrhoeae and $C$ trachomatis tests; he contributed to the design of the study and analysis of the data; JSJ was responsible for the $M$ genitalium tests; he provided major contributions to the design of the study and analysis of the data.

\section{Authors' affiliations}

L Falk, Department of Dermatology and Venereology, University Hospital, Örebro, Sweden

H Fredlund, Department of Clinical Microbiology and Immunology, University Hospital, Örebro, Sweden

J S Jensen, Mycoplasma Laboratory, Statens Serum Institut, Copenhagen, Denmark

Funded by the Research Committee of Örebro County Council, Örebro Medical Centre Research Foundation. The research ethics committee of Örebro County Council approved the first part of the study 1 November 1999 and the second part of the study 27 August 2002.

Conflict of interest: none declared.

\section{REFERENCES}

1 Tully JG, Taylor-Robinson D, Cole RM, et al. A newly discovered mycoplasma in the human urogenital tract. Lancet $1981 ; 1: 1288-91$.

2 Taylor-Robinson D. Mycoplasma genitalium - an up-date. Int J STD AIDS 2002;13:145-51

3 Jensen JS, Ørsum R, Dohn B, et al. Mycoplasma genitalium: a cause of male urethritis? Genitourin Med 1993;69:265-9.

4 Biörnelius E, Lidbrink P, Jensen JS. Mycoplasma genitalium in non-gonococcal urethritis-a study in Swedish male STD patients. Int J STD AIDS 2000;11:292-6.

5 Johannisson G, Enström Y, Löwhagen GB, et al. Occurrence and treatment of Mycoplasma genitalium in patients visiting STD clinics in Sweden. Int J STD AIDS 2000;11:324-6.

6 Horner P, Thomas B, Gilroy CB, et al. Role of Mycoplasma genitalium and Ureaplasma urealyticum in acute and chronic nongonococcal urethritis. Clin Infect Dis 2001;32:995-1003.
7 Taylor-Robinson D, Horner P. The role of Mycoplasma genitalium in nongonococcal urethritis. Sex Transm Infect 2001;77:229-31.

8 Dupin N, Bijaoui G, Schwarzinger M, et al. Detection of Mycoplasma genitalium in male patients with urethritis. Clin Infect Dis 2003;37:602-5.

9 Manhart LE, Critchlow CW, Holmes KK, et al. Mucopurulent cervicitis and Mycoplasma genitalium. J Infect Dis 2003;187:650-7.

10 Cohen CR, Manhart LE, Bukusi EA, et al. Association between Mycoplasma genitalium and acute endometritis. Lancet 2002;359:765-6.

11 Simms I, Eastick K, Mallinson H, et al. Associations between Mycoplasma genitalium, Chlamydia trachomatis, and pelvic inflammatory disease. Sex Transm Infect 2003:79:154-6.

12 Clausen HF, Fedder J, Drasbek M, et al. Serological investigation of Mycoplasma genitalium in infertile women. Hum Reprod 2001;16:1866-74

13 Casin I, Vexiau-Robert $D$, de la Salmonière $P$, et al. High prevalence of Mycoplasma genitalium in the lower genital tract of women attending a sexually transmitted disease clinic in Paris, France. Sex Transm Dis 2002;29:353-9.

14 Pépin J, Sobéla F, Deslandes S, et al. Etiology of urethral discharge in West Africa: the role of Mycoplasma genitalium and Trichomonas vaginalis. Bull World Health Organ 2001;79:118-26.

15 Falk L, Fredlund H, Jensen JS. Symptomatic urethritis is more prevalent in men infected with Mycoplasma genitalium than with Chlamydia trachomatis. Sex Transm Infect 2004;80:289-93.

16 De Allende I, Orías $O$. Cytology of the human vagina. Hoeber Inc, 1950:53-74.

17 Larsson PG, Platz-Christensen JJ. The vaginal pH and leucocyte/epithelial ratio vary during normal menstrual cycles. Eur J Obstet Gynecol Reprod Biol ratio vary during

18 Swartz SL, Kraus SJ, Herrmann KL, et al. Diagnosis and etiology of nongonococcal urethritis. J Infect Dis 1978;138:445-54.

19 Jensen JS, Borre MB, Dohn B. Detection of Mycoplasma genitalium by PCR amplification of the 16S rRNA Gene. J Clin Microbiol 2003;41:261-6.

20 Jensen JS, Uldum SA, Sondergard-Andersen J, et al. Polymerase chain reaction for detection of Mycoplasma genitalium in clinical samples. J Clin Microbiol 1991;29:46-50.

21 Swedish Institute for Infectious Disease Control. Annual Report. SMI, Stockholm, Sweden: Swedish Institute for Infectious Disease Control, 2000.

22 Amsel R, Totten PA, Spiegel CA, et al. Nonspecific vaginitis. Diagnostic criteria and microbial and epidemiologic associations. Am J Med 1983;74:14-22.

23 Falk L, Fredlund $\mathrm{H}$, Jensen JS. Tetracycline does not eradicate Mycoplasma genitalium. Sex Transm Infect 2003:79:318-319.

24 Anagrius C, Loré B. Mycoplasma genitalium - viktig och vanlig sexuellt överförd sjukdom. (In Swedish). Lakartidningen 2002;99:4854-9.

25 Cates WJ Jr, Wasserheit JN. Genital chlamydial infections; epidemiology and reproductive sequelae. Am J Obstet Gynecol 1991;164:1771-81.

26 Spence MR. Gonorrhea. Clin Obstet Gynecol 1983;26:111-24.

27 Wiesenfeld HC, Hillier SL, Krohn MA, et al. Bacterial vaginosis is a strong predictor of Neisseria gonorrhoeae and Chlamydia trachomatis infection. Clin Infect Dis 2003:36:663-8.

28 Keane FE, Thomas BJ, Gilroy CB, et al. The association of Mycoplasma hominis, Ureaplasma urealyticum and Mycoplasma genitalium with bacterial vaginosis: observations on heterosexual women and their male partners. Int J STD AIDS 2000:11:356-60.

29 Stamm W. Chlamydia trachomatis infections of the adult. In: Holmes K, Sparling F, Mårdh PA, et al, eds. Sexually transmitted diseases, 3rd ed. New York: McGraw-Hill, 1999:407-22.

30 Brunham RC, Paavonen J, Stevens CE, et al. Mucopurulent cervicitis-the ignored counterpart in women of urethritis in men. N Engl J Med 1984;311:1-6.

\section{Register now!}

10th European Forum on Quality Improvement in Health Care

13-15 April 2005, ExCel Conference Centre, London

For further information on how to submit your paper please go to:

http://www.quality.bmipg.com 